\title{
Correction to: The cultural neuroscience of emotion regulation
}

\section{Ryan S. Hampton ${ }^{1} \cdot$ Michael E. W. Varnum ${ }^{1}$}

Published online: 9 August 2018

(C) Springer-Verlag GmbH Germany, part of Springer Nature 2018

\section{Correction to: Culture and Brain https://doi.org/10.1007/s40167-018-0066-2}

In the original publication, there were several content and grammatical errors in Table 1. The corrected Table 1 is given below:

The original article can be found online at https://doi.org/10.1007/s40167-018-0066-2.

$\triangle$ Ryan S. Hampton rshampt1@asu.edu

$\triangle$ Michael E. W. Varnum mvarnum@asu.edu

1 Arizona State University, Tempe, AZ, USA 
Table 1 Summary of cultural neuroscience studies on emotion regulation

\begin{tabular}{|c|c|c|c|c|c|}
\hline Study & Total N & $\begin{array}{l}\text { Sample } \\
\text { composition }\end{array}$ & Methods & Stimuli & Task structure \\
\hline $\begin{array}{l}\text { Ohira et al. } \\
(2006)\end{array}$ & $\mathrm{N}=10$ & Female Japanese & $\begin{array}{l}\text { fMRI, heart } \\
\text { rate, and } \\
\text { skin } \\
\text { conductance }\end{array}$ & $\begin{array}{l}60 \text { moderately } \\
\text { arousing } \\
\text { positive, } \\
\text { negative, and } \\
\text { neutral IAPS } \\
\text { images }\end{array}$ & $\begin{array}{l}\text { Attend followed by } \\
\text { suppress }\end{array}$ \\
\hline $\begin{array}{l}\text { Goldin } \\
\text { et al. } \\
(2008)\end{array}$ & $\mathrm{N}=17$ & Female Americans & fMRI & $\begin{array}{l}40 \text { neutral and } \\
\text { disgust- } \\
\text { inducing } 15-\mathrm{s} \\
\text { film clips }\end{array}$ & $\begin{array}{l}\text { Pseudo-randomized } \\
\text { order of watch. } \\
\text { suppress, and } \\
\text { reappraise }\end{array}$ \\
\hline $\begin{array}{l}\text { Qu and } \\
\text { Telzer } \\
(2017)\end{array}$ & $\mathrm{N}=29$ & $\begin{array}{l}\text { European } \\
\text { Americans and } \\
\text { Chinese }\end{array}$ & fMRI & $\begin{array}{l}32 \text { naturalistic } \\
\text { visual scenes } \\
\text { of people in } \\
\text { emotionally } \\
\text { negative } \\
\text { situations }\end{array}$ & $\begin{array}{l}\text { Think of person in } \\
\text { photo as self, } \\
\text { reappraise } \\
\text { (increase/ } \\
\text { decrease), then } \\
\text { emotion rating }\end{array}$ \\
\hline $\begin{array}{l}\text { Soto et al. } \\
\text { (2016) }\end{array}$ & $\mathrm{N}=59$ & $\begin{array}{l}\text { Asian and European } \\
\text { Americans }\end{array}$ & $\begin{array}{l}\text { EKG } \\
\text { interbeat } \\
\text { interval and } \\
\text { skin } \\
\text { conductance }\end{array}$ & $\begin{array}{l}5 \text { neutral and } \\
\text { disgust- } \\
\text { inducing } \\
52-62 \text { s film } \\
\text { clips }\end{array}$ & $\begin{array}{l}\text { Neutral, disgust- } \\
\text { watch, disgust- } \\
\text { suppress/-amplify } \\
\text { counterbalanced, } \\
\text { neutral }\end{array}$ \\
\hline $\begin{array}{l}\text { Murata } \\
\text { et al. } \\
(2011)\end{array}$ & $\mathrm{N}=34$ & $\begin{array}{l}\text { European } \\
\text { Americans and } \\
\text { East Asians }\end{array}$ & EEG & $\begin{array}{l}120 \text { neutral and } \\
\text { mutilation/ } \\
\text { threat IAPS } \\
\text { images }\end{array}$ & $\begin{array}{l}\text { Attend followed by } \\
\text { suppress }\end{array}$ \\
\hline $\begin{array}{l}\text { Varnum } \\
\text { and } \\
\text { Hampton } \\
\text { (2017) }\end{array}$ & $\mathrm{N}=55$ & $\begin{array}{l}\text { European } \\
\text { Americans and } \\
\text { East Asians }\end{array}$ & EEG & $\begin{array}{l}162 \text { neutral, } \\
\text { high-arousal } \\
\text { negative, and } \\
\text { positive IAPS } \\
\text { images }\end{array}$ & $\begin{array}{l}\text { Attend followed by } \\
\text { counterbalanced } \\
\text { suppress and } \\
\text { enhance }\end{array}$ \\
\hline $\begin{array}{l}\text { Hampton } \\
\text { et al. } \\
\text { (2018) }\end{array}$ & $\mathrm{N}=146$ & $\begin{array}{l}\text { European } \\
\text { Americans, } \\
\text { Chinese/Chinese- } \\
\text { Americans and } \\
\text { Mexican/Mexican } \\
\text { Americans }\end{array}$ & EEG & $\begin{array}{l}108 \text { high- } \\
\text { arousal } \\
\text { negative and } \\
\text { positive IAPS } \\
\text { images }\end{array}$ & $\begin{array}{l}\text { Attend followed by } \\
\text { counterbalanced } \\
\text { suppress and } \\
\text { enhance }\end{array}$ \\
\hline
\end{tabular}

Note This table lists the studies described in this paper with the sample characteristics, methods used, and stimuli/task structures. Samples contain both females and males unless otherwise specified 